\title{
THE RATIONALITY OF ANTIBIOTICS THERAPY TOWARD CHILDREN WITH TYPHOID FEVER AT M.M. DUNDA HOSPITAL
}

\section{TETI SUTRIYATI TULOLI*, DEWI R MOO}

Department of Pharmacy, Faculty of Sport and Health, State University of Gorontalo, Indonesia. Email: tetisutriyati@gmail.com Received: 05 March 2018, Revised and Accepted: 03 April 2018

\section{ABSTRACT}

Objectives: Typhoid fever is an acute systemic infectious disease in the small intestine caused by Salmonella enterica serotype typhi (Salmonella typhi) having the symptoms of fever a week or more with impairment of the gastrointestinal tract with or without impaired consciousness. The purpose of this study was to determine the rationality of antibiotic therapy in pediatric patients at M.M Dunda Limboto Hospital.

Methods: This research belongs to non-experimental descriptive with retrospective data retrieval. The data used were obtained from 83 medical records of childhood typhoid patients during 6 months (June-November 2016) at the regional general hospital of M.M Dunda Limboto. These data were analyzed using the Gyssens criteria.

Results: The results showed that the most antibiotics used by physicians were ceftriaxone $39 \%$ of the use of antibiotic quality which was category IIB 9\%, category IIA 13\%, and category 0 (rational) 52\%.

Conclusion: The rationality of antibiotic therapy in children with typhoid fever at M.M Dunda Limboto Hospital was $52 \%$ of the most antibiotics used, i.e. ceftriaxone (39\%).

Keywords: Antibiotic, Dunda limboto, Rationality, Typhoid, Therapy.

(C) 2018 The Authors. Published by Innovare Academic Sciences Pvt Ltd. This is an open access article under the CC BY license (http://creativecommons. org/licenses/by/4. 0/) DOI: http://dx.doi.org/10.22159/ajpcr.2018.v11i7.25631

\section{INTRODUCTION}

Typhoid fever is a global problem, especially in developing countries. The main cause is Salmonella typhi that contaminates food and drink and poor environmental sanitation system [1,2]. Globally, it has been recorded that there are 17 million cases of typhoid with a total of 600,000 death cases from typhoid. In Asia, more than 13 million people are infected by typhoid, a systemic and endemic disease [3].

The incidence of typhoid fever in Indonesia is still very high, ranging between 358 and 810 per 100,000 population, as well as from cases of typhoid fever in major hospitals in Indonesia, indicating that the rate of typhoid fever tends to increase every year with the average of $500 / 100,000$ inhabitants. The typhoid fever death rate is estimated to occur around $0.6-2 \%$ as a result of delayed treatment and the high cost of treatment [4]

Based on the health profile of Indonesia people in 2010 by the Ministry of Health of the Republic of Indonesia showed typhoid fever ranked the third of 10 inpatient diseases in hospitals in Indonesia as many as 41,081 cases of 274 people died. The highest incidence rates of typhoid fever occurred in children and young adults in the 5-34 years' age range [5]. The highest morbidity rate was the age of 5-19 years with mild clinical manifestations. In pediatric patients with this typhoid, diagnosis was used antibiotics and other supporting drugs as typhoid therapy [6].

In a study of pediatric patients suffering from typhoid fever at Fatmawati Hospital, Jakarta, in 2001-2002, it was found that chloramphenicol was still the primary choice used in childhood typhoid fever. Meanwhile, ceftriaxone was the second choice antibiotic which used by physician. In December 2002 based on the results of preliminary observation at M.M Dunda hospital, data obtained from June-November 2016 about typhoid fever occupied the first position of 10 the most diseases in hospitalization M.M Dunda with the number of patients as many as 628 patients who given cephalosporin antibiotics
The antibiotic prescription in Indonesia is quite high which is likely to trigger a rise in cases of antibiotic resistance. The impact of antibiotics resistance is the increase in patient morbidity and mortality. In the past decade, many microorganisms have been resistant to antibiotics that exist in some therapeutic standards. This is a phenomenon occurring almost all over the world caused by excessive abuse and antibiotics use [7]. Based on the above description, the researcher felt that it was necessary to evaluate the rationality of antibiotic therapy in child fever at M.M Dunda to support the success of typhoid therapy and reduce the appearance of resistant microorganisms against antibiotics.

\section{METHODS}

This research was conducted in Medical Record Room at Regional General Hospital of M.M DundaLimboto. The study was conducted in January-May 2017. This type of research is analytical descriptive with the retrospective approach.

The population in this study was all pediatric typhoid children using antibiotic therapy during June-November 2016 at The Regional General Hospital of M.M Dunda Limboto. Data collected from the medical record included the name of antibiotics, diagnosis, dosage, frequency, administration duration, route of administration, number of antibiotic combinations, demographic data, and clinical data.

The data obtained were analyzed qualitatively using the Gyssens category [8]. This category consisted of 12 categories such as category 0: Appropriate/rational antibiotic use, category I: Irrational due to inappropriate timing, category IIA: Irrational due to inaccurate dosage, category IIB: Irrational due to incorrect interval, category IIC: Irrational due to wrong way of giving, category IIIA: Irrational due to prolonged giving, category IIIB: Irrational due to too short giving, category IVA: Irrational due to other more antibiotics effective, category IVB: Irrational due to other antibiotics less toxic, category IVC: Irrational because of other antibiotics cheaper, category IVD: Irrational because 
of other antibiotics more specific, and category V: Irrational due to the absence of indications for antibiotics use. The results of the analysis will be presented in the form of a percentage of the accuracy or the absence of antibiotics. This research has obtained the recommendation of ethical approval No. 017/KEPK/SG/02/2018 from the Health Research Ethics Commission of Yogyakarta Health Sciences College.

\section{RESULTS}

This study obtained 83 medical records at M.M Dunda Hospital which met the criteria for inclusion with the prescription of antibiotics 90 items of antibiotics. Demographic characteristics of study respondents can be seen in Table 1 .

Based on Table 1, it was known that the respondents of pediatric patients with female sex were more dominant (64\%) than the number of respondents of child patients of male sex (36\%). Based on the age group showed that the incidence of typhoid infections were the highest at the age of 5-10 years about $54 \%$ and the lowest at the age of $11-14$ years around $8 \%$.. The results of this study indicated that as children age, the incidence of infection decreases. Children are infected 3-6 times a year although some children were infected more often than children of 2-3 years age range, and the incidence of infection in children of this age occurred because the immune system in this child was not fully developed to prevent infection [9].

This study showed that there are four types of antibiotics that have been prescribed in patients with typhoid fever with the number of antibiotics classified as dominant were ceftriaxone (39\%) and cefotaxime (32\%). The dominant use of the third-generation cephalosporin class (ceftriaxone) in typhoid fever was due to a faster cure rate in ceftriaxone therapy than on chloramphenicol therapy of 7 days and the absence of a relapse possibility for patients with ceftriaxone therapy for 8-14 day [10]. Surveys of several strains of bacteria in several South Asian countries between 2002 and 2004 revealed that $23 \%$ of bacterial strains have been resistant to chloramphenicol, ampicillin, and trimethoprim-sulfamethoxazole [11]. Yet, other studies also showed that the prevalence of resistance to some antibiotics varied from $0 \%$ to $50 \%[12]$

Pediatric patients in this study also received a number of different antibiotics such as patients with single antibiotics $85.5 \%$ and patients who get two combinations of antibiotics $14.5 \%$ and this is shown in Table 2. The purpose of the use of this antibiotics combination is to increase the efficacy of antibiotics in typhoid infections.

The rationality assessment of the use of antibiotics qualitatively in this study was conducted using the criteria of Gyssens (Table 3). The highest analysis result was the category 0 (rational) of $52 \%$ followed by the category IIIB (administration of antibiotics too short) of $26 \%$, followed by the category IIA (13\% unnecessary administration of antibiotics).

Meanwhile, the data also showed that there were no antibiotics therapy in typhoid fulfilled category $\mathrm{V}$ (antibiotics without indication), IVD (more specific antibiotics), IVC (cheaper antibiotics), IVB (more toxic), IIIA (long administration), IIC (not exact way of administration), and I (time is not appropriate). So that in all of these categories got 0 . In category IIIB, there were $23(26 \%)$ antibiotic treatments which considered to be overvalued assuming. This could lead to ineffective therapy. For category IIB, there was eight antibiotic therapies (9\%) which were assessed not exactly the interval, while category IIA gave 12 antibiotic therapies (13\%) which assessed not exactly dose. For category 0 , there was 47 antibiotics therapies (52\%) that were considered rational both in terms of administration time, dose, interval, and the way of antibiotics.

\section{DISCUSSION}

Demographic characteristics of respondents in this study were assessed by sex and age range of children with typhoid at M.M. Dunda. In this study, it was found that pediatric patients with female sex $(64 \%)$ had
Table 1: The characteristic of respondents

\begin{tabular}{ll}
\hline The characteristic & $\mathbf{N}(\%)$ \\
\hline Gender & \\
Female & $53(64)$ \\
Male & $30(36)$ \\
Total & $83(100)$ \\
Age & \\
1-4 years & $30(36)$ \\
5-10 years & $45(54)$ \\
11-14 years & $8(10)$ \\
Total & $83(100)$ \\
\hline
\end{tabular}

Table 2: The therapy of antibiotics on children thypoid patients

\begin{tabular}{ll}
\hline Variable & $\mathbf{N}(\%)$ \\
\hline Antibiotics & \\
Vicilin & $17(19)$ \\
Cefotaxime & $29(32)$ \\
Cefixime & $9(10)$ \\
Ceftriaxone & $35(39)$ \\
Total & $90(100)$ \\
Antibiotics combination & $77(85.5)$ \\
Single & $13(14.5)$ \\
Double & $90(100)$ \\
Total &
\end{tabular}

Table 3: The rationality of antibiotics therapy based on Gyssens category (2001)

\begin{tabular}{ll}
\hline The category of therapy rationality & Total \\
\cline { 2 - 2 } & $\mathbf{N}(\%)$ \\
\hline 0=Rational & $47(52)$ \\
I=Not on time & $0(0)$ \\
II A=Not exactly dose & $12(13)$ \\
II B=Not exactly interval & $8(9)$ \\
II C=Not exactly administration & $0(0)$ \\
III A=Giving too long & $0(0)$ \\
III B=Giving too short & $23(26)$ \\
IV A=More effective antibiotics & $0(0)$ \\
IV B=More toxic antibiotics & $0(0)$ \\
IV C=Cheaper antibiotics & $0(0)$ \\
IV D=More specific antibiotics & $0(0)$ \\
V=Antibiotics without indication & $0(0)$ \\
Total & $90(100)$ \\
\hline
\end{tabular}

more numbers than the number of male children (36\%). Typhoid fever disease can affect anyone, and there is no difference between sex and female.

In general, the typhoid disease was more common in children suffering than adults, in adulthood, often experience symptoms that are not typical, and then disappear or heal itself [10]. The results of this study were not in line with previous research, stating that children diagnosed with typhoid fever were more common in male sex (58\%). This was partly due to the type of activity, living habits, and physiological conditions of each individual [13].

Based on data showed that the incidence of typhoid fever was in the range of age varying with the highest number existed at the age of $5-10$ years $(54 \%)$ and the lowest at the age range $11-14$ years $(10 \%)$. This study showed that the increase of children age of the incidence of typhoid fever was reduced. This was in line with previous research findings that the rate of infection in children decreased on age [7]

It can be seen that antibiotics often prescribed in the treatment of typhoid fever were ceftriaxone (39\%), cefotaxime (32\%), vicilin (19\%), and cefixime $(10 \%)$. Pediatric patients also received a combination 
of two antibiotics (14.5\%) and a single antibiotic (85.5\%). The most commonly prescribed antibiotic combination was vicilin-cefotaxime (7.8\%). Both of these antibiotics have the same characteristics that are equally bactericidal, having the same mechanism of action that inhibits the synthesis of bacterial cell walls, as well as both of these antibiotics having lactam beta rings on their molecular structure. In general, both antibiotics are active against Gram-positive and Gram-negative bacteria. The choice of cefotaxime to be combined with vicilin is caused by cefotaxime which is a third-generation cephalosporin and tends to be more active against Gram-negative bacteria such as $S$. typhi so that if both these antibiotics are combined, it will obtain synergistic results in overcoming the bacteria causing typhoid fever. However, the use of cefotaxime to be combined with vicilin which is advisable to do a skin test in advance to avoid the possibility of cross-reactivity due to the use of cephalosporin in patients hypersensitive to beta-lactam antibiotics.

The use of a single antibiotic, the administration of ceftriaxone in the treatment of typhoid fever is more preferable than chloramphenicol because ceftriaxone is not easy to cause resistance having minimal side effects and clinical efficacy. Ceftriaxone can decrease fever more quickly causing the duration of therapy was shorter than chloramphenicol. This is assumed to cause ceftriaxone more preferred than other reasons that the possibility of multidrug-resistant $S$. typhi (MDRST). MDRST is the preferred resistance of antibiotics in the treatment of typhoid fever which caused by the use of irrational antibiotics and intrinsic factor changes in microbes. Ceftriaxone is the preferred antibiotic used in the event of MDRST. In addition, chloramphenicol also has side effects such as bone marrow suppression and aplastic anemia [14].

The second sequence, the most widely used antibiotics for typhoid therapy, is cefotaxime [15]. Cefotaxime is used in patients with severe typhoid fever who are quinolone-resistant. Cefotaxime and ceftriaxone are effective for the treatment of Gram-negative bacteria such as S. typhi [16]. This reason allows ceftriaxone and cefotaxime to be used at M.M. Dunda Limboto. The results of this study were related to cefotaxime which was the most widely used antibiotic for the treatment of typhoid fever in pediatric patients. Cefotaxime is class III cephalosporin group that has a very wide spectrum, its antibacterial activity is stronger, and side effects are relatively lower [17].

Viciline is also used for the treatment of typhoid fever of inpatients. Besides that, amoxicillin and ampicillin have the same spectrum and antibacterial activity. However, in terms of the ability to reduce fever, the effectiveness of amoxicillin and ampicillin is smaller than chloramphenicol [18]. Finally, cefixime is an antibiotic that is also used to treat therapies in patients with typhoid fever at M.M. Dunda. Cefixime is a third-generation cephalosporin antibiotic that is stable against the $\beta$-lactamase enzyme produced by organisms such as Streptococcus strains, Haemophilus influenza, Neisseria gonorrhoeae, and the majority of Enterobacteriaceae. This antibiotic is bactericidal with a broad spectrum of Gram-positive bacteria (Streptococcus sp. and Streptococcus pneumonia) and Gram-negative (E. coli, Proteus sp., and Haemophilus influenza). The cefixime activity decreases against Staphylococcus aureus, Enterococci, Listeria monocytogenes, and Pseudomonas spp. The incidence of cefixime-resistant bacteria is reported to be very low. Cefixime may be used as an alternative medicine for the treatment of typhoid fever, especially unless chloramphenicol cannot be given (e.g., leukocyte count) [19].

Assessment of rationality level of antibiotics in this study uses Gyssens criteria. This Gyssens method takes into account several components: Therapeutic indications, antibiotic characteristics (efficacy, safety of use, price, and spectrum), dose, interval, and time of administration. After the assessment with criteria, Gyssens obtained the results of the use of antibiotics for the therapy of child on typhoid fever which can be seen in Table 3. A total of 47 prescriptions (52\%) fall into category 0 , i.e., the rational use of antibiotics in which antibiotics are given a clear indication relating to the patient's needs (assessed for efficacy, safety, suitability and cost), dose, appropriate intervals and delivery routes and time. Meanwhile, the previous studies showed 32\% of children with typhoid receiving rational antibiotic therapy [7].

The use of antibiotics for the treatment of childhood typhoid fever was $13 \%$ of the category IIA, which is the dose used was not appropriate well beyond the maximum dose or below the maximum dose. Based on clinical practice guidance of child health sciences of M.M. Dunda was the doses of ceftriaxone should be given $50 \mathrm{mg} / \mathrm{kg} \mathrm{BW}$, ampicilin $200 \mathrm{mg} / \mathrm{kg} \mathrm{BW}$ and amoxicillin $100 \mathrm{mg} / \mathrm{kg} \mathrm{BW}$, cefixime $20 \mathrm{mg} / \mathrm{kg} \mathrm{BW}$, chloramphenicol $75 \mathrm{mg} / \mathrm{kg}$ BW. Doses may be under maximum doses such as the use of ceftriaxone which is dose for children $50 \mathrm{mg} / \mathrm{kg} \mathrm{BW}$ but body weight $19 \mathrm{~kg}$ of children should be given ceftriaxone with a dose of $950 \mathrm{mg} /$ day and $475 \mathrm{mg}$ for single dose because ceftriaxone is given every 12 hours but in the treatment is given only $380 \mathrm{mg} /$ day and $190 \mathrm{mg}$ for single dose. The condition is also adjusted to the form of antibiotic preparations used to suppress the cost of patient therapy. The results obtained in the study were high category which compared with previous studies obtaining the results that the use of antibiotics for Bengkulu hospital $0.6 \%$ belonging to not exactly dose [7]

The study showed that there were eight prescribers (9\%) who entered in the category IIB having the inappropriate antibiotics interval. Based on the clinical practice guidelines of children's health sciences of M.M. Dunda stated that ceftriaxone $50 \mathrm{mg} / \mathrm{kg}$ BW which given 2 times daily or $80 \mathrm{mg} / \mathrm{kg}$ BW, once daily intravenously for 5-7 days. Meanwhile, we obtained the example of ceftriaxone which was given 3 times a day in children weighing $19 \mathrm{~kg}$. The results of this study in the IIB category were judged to be greater when compared with previous studies, showing that $6.8 \%$ of prescribed antibiotics were not used properly, in part, because of incorrect therapy duration or incorrect dose intervals [20].

Based on the Gyssens criteria used in this study described there were 23 prescriptions (26\%) belonging to IIIB criteria (giving too short). This is related to the clinical practice guidelines of children's health sciences of M.M. Dunda. Whereas, according to the WHO, it is stated that the use of ceftriaxone to achieve optimal therapy was 10-14 days [8], for example, for giving too short of administration of antibiotics ceftriaxone 2 times a day with a dose of $225 \mathrm{mg}$ in patients having body weight $9 \mathrm{~kg}$ and given only for 2 days. In Indonesia, the use of antibiotics is in the range of 3-7 days to kill disease-causing microbes $[7,21]$. If the treatment was done too short, the therapy will not be optimal and in the long run which will cause the resistance of antibiotics.

\section{CONCLUSION}

The rationality of antibiotics therapy in childhood typhoid fever at M.M. Dunda Limboto Hospital was $52 \%$ of the most antibiotics use, i.e., ceftriaxone (39\%).

\section{AUTHORS' CONTRIBUTION}

Mrs. Teti ST - Review of literature and Data analysis. Mrs. Dewi RM - Data Collection.

\section{CONFLICTS OF INTEREST}

All authors have none to declare.

\section{REFERENCES}

1. KalraNaithaniMehtaSwamyJohn S, GunnJM, MarshallStephen BSabina DRichelle C, CharlesEdward T. AkhloufiRH,StreefkerkDC,MellesJEM. SteenwinkelCAM,SchurinkRP. VerkooijenCP, Van DHVerbon1. Wain J, Hendriksen RS, Mikoleit ML, Keddy KH, Ochiai RL. Typhoid Fever. Lancet 2015;385:1136-45.

2. PanditRK, Gupta D, Mukherjee T. Identifications of potential Salmonella typhi Beta-lactamase TEM inhibitors using peptidomimetics, virtual screening and molecular dynamics simulations. Int J Pharm Pharm Sci 2018;10:91-6.

3. Sinha A, Sazawal S, Kumar R, Sood S, Reddaiah VP, Singh B, et al. 
Typhoid fever in children aged less than 5 years. Lancet 1999;354:734-7.

4. Punjabi NH. Cost evaluation of typhoid fever in Indonesia. Med J Ind 1998;7:90-3.

5. Simanjuntak CH. Typhoid Fever, Epidemiology and Development Research. The Mirror of Medicine Word 83. Jakarta: Garuda Portal Press; 2009.

6. Musnelina L, Fuad A, Ascobat G, Pratiwi A. The pattern of antibiotics treatment for child typhoid fever at fatmawati Hospital. J Inst Sains Tech Natl 2004;59:130-5.

7. Muslim Z, Meinisasti R. Rationality of antibiotic usage in paediatrics in Bengkulu, Indonesia: Gyssens' criteria and type oftherapy analysis. Indian J Pharm Sci 2016;78:840-4.

8. Gyssens IC, Van Den Broek PJ, Kullberg BJ, Hekster Y, Van Der Meer JW. Optimizing antimicrobial therapy: A method for antimicrobial drug use evaluation. J Antimicrob Chemother 2005;30:724-7.

9. BNF. For Children. London: British National Formulary Publications, Royal Pharmaceutical Society of Great Britain; 2009.

10. Tatli MM, Aktas G, Kosecik M, Yilmaz A. Treatment of typhoid fever in children with a flexible duration of ceftriaxone, compared with a 14-day treatment with chloramphenicol. Int J Antimicrob Agents 2003;21:350-3.

11. Ochiai RL, Acosta CJ, Danovaro-Holliday M, Baiqing D, Bhattacharya SK, Agtini MD, et al. A study of typhoid fever in five Asian Countries: Disease burden and implications for controls. Bull World Health Organ 2008;86:260-8.

12. Chau TT, Campbell JI, Galindo CM, et al. Antimicrobial drug resistance of Salmonella enterica serovartyphi in Asia and molecular mechanism of reduced susceptibility to the fluoroquinolones. Antimicrob Agents Chemother 2007;51:4315-23.
13. Khanam F, Sayeed MD, Feroza KC, Alaullah SDA, Doli G, Lokman H, Abdullah B, Stephen BC, Richelle CC, Alejandro CET, Ryan, Firdausi Q. Typhoid Fever in Young Children in Bangladesh: Clinical Findings, Antibiotic Suspectibility Pattern And Immune Responses. Plos Neglected Tropical Disease. 2015;4:1-11.

14. Sucindar M, Kumaran SS. Profile of culture enteric fever in children admitted in a tertiary care hospital. J Evol Med Dent Sci 2017;6:278-802.

15. World Health Organization. Background Document: The Diagnosis, Treatment and Prevention of Typhoid Fever. Geneva Switzerland: WHO; 2003.

16. Rajesh U, Milind Y, Nadkar A, Muruganathan A, Mangesh T, Deepak A, Banka AN, et al. Api recommendations for the management of typhoid fever. J Assoc Phys India 2015:63:267.

17. Kalra SP, Naithani N, Mehta SR, Swamy AI. Current trends in the management of typhoid fever. Med J Armed Forces India 2003;59:130-5.

18. Gunn JS, Marshall JM, Stephen B, Sabina D, Charles RC, Edward T. Salmonella Chronic carriage: Epidemiology, diagnosis and gallbladder persistence. Trends Microbiol 2014;22:648-55.

19. Mukesh KC, Singh R, Kusum P, Pratiksha B, Ram SC, Suvash G. Efficacy of cefixime in the treatment of typhoid fever. Int J Pharm Bio Arch 2013;4:325-7.

20. Akhloufi RH, Streefkerk DC, Melles JE, Steenwinkel CA, Schurink RP, Verkooijen $\mathrm{CP}$, et al. Point prevalence of appropriate antimicrobial therapy in a dutch university hospital. Eur J Clin Microbiol Infect Dis 2015;34:1631-7.

21. Shamin MD, Ali MD, Ahmad S, Ansari SM. Drug utilization based ADRS detection of antibiotics prescribed for LRTi in tertiary care teaching hospital New Delhi. Int J Pharm Pharm Sci 2018;10:7-14. 